\title{
Catalytic oxidation of benzyl alcohol on Au or Au-Pd nanoparticles confined in mesoporous silica
}

\author{
Chun Yan Ma ${ }^{a}$, Bao Juan Dou ${ }^{a}$, Jin Jun $\mathrm{Li}^{\mathrm{a}}$, Jie Cheng ${ }^{\mathrm{a}}$, Qin $\mathrm{Hu}^{\mathrm{a}}$, Zheng Ping Hao ${ }^{\mathrm{a}, *}$, Shi Zhang Qiao ${ }^{\mathrm{b}, * *}$ \\ ${ }^{a}$ Research Center for Eco-Environmental Sciences, Chinese Academy of Sciences, Beijing 100085, PR China \\ ${ }^{\mathrm{b}}$ Australian Research Council (ARC) Centre of Excellence for Functional Nanomaterials, School of Engineering and Australian Institute for Bioengineering and Nanotechnology, \\ The University of Queensland, Brisbane, QLD 4072, Australia
}

\section{A R T I C L E I N F O}

\section{Article history:}

Received 15 May 2009

Received in revised form 29 June 2009

Accepted 10 July 2009

Available online 17 July 2009

\section{Keywords:}

Gold and palladium

Mesoporous SBA-15

Nanoparticles

Oxidation

Benzyl alcohol

\begin{abstract}
A B S T R A C T
In this paper, we report the synthesis of $\mathrm{Au} / \mathrm{SBA}-15$ and $\mathrm{Au}-\mathrm{Pd} / \mathrm{SBA}-15$ materials by impregnation and grafting methods. It was found that the Au-Pd/SBA-15 sample prepared by the grafting method could highly disperse metal nanoparticles in mesoporous channels of SBA-15 and exhibit excellent catalytic performances for the selective oxidation of benzyl alcohol to benzaldehyde at mild reaction conditions (air atmosphere, $80^{\circ} \mathrm{C}$ ). The prevention of agglomeration and leaching of gold nanoparticles by restricting them inside the mesopores of SBA- 15 leads to a high stability of Au-Pd/SBA- 15 . In both approaches, the addition of Pd to Au/SBA-15 catalysts can decrease the size of gold nanoparticles, which attributes to higher activity for the selective aerobic oxidation of benzyl alcohol.
\end{abstract}

(c) 2009 Elsevier B.V. All rights reserved.

\section{Introduction}

The oxidation of alcohols into their corresponding aldehydes and ketones is of significant importance in both laboratory and industrial synthetic chemistry [1]. Many oxidizing agents have been used, e.g., hypochlorite [2], chromium(VI) oxide [3], dichromate [4], manganese(IV) oxide [5] and permanganate [6]. These stoichiometric oxidants, however, feature serious drawbacks as they are expensive and/or toxic and produce a large amount of waste. The present stringent ecological standards have forced researchers to develop new environmentally benign methods. Accordingly, a remarkable number of metal-catalyzed aerobic processes, especially based on Pd [7-9], Ru [10-12], and $\mathrm{Cu}[13,14]$ complexes, have been developed. In recent years, the unexpectedly high activity of $\mathrm{Au}$ as a lowtemperature $\mathrm{CO}$ oxidation catalyst [15] has initiated intensive research in the use of Au nanoparticles for the liquid-phase oxidation of alcohols [16-20].

In comparative studies of aqueous-phase aerobic catalytic oxidation of alcohol using supported Pt, Pd, or $\mathrm{Au}$ as a catalyst, Au had the highest selectivity and was less prone to metal leaching, over-oxidation, and self-poisoning by strong adsorbed byproducts. The higher selectivity and absence of catalyst deactivation are

\footnotetext{
* Corresponding author. Tel.: +86 10 62849194; fax: +86 1062923564 .

** Corresponding author. Tel.: +61 7 33463809; fax: +61 733463973.

E-mail addresses: zpinghao@rcees.ac.cn (Z.P. Hao), s.qiao@uq.edu.au (S.Z. Qiao).
}

probably due to the weaker adsorption of oxygen, hydrogen, reactant, and products on Au [21,22]. Generally, the adsorption and catalytic properties of Au strongly depend on its particle size, which can be controlled by the preparation method and type of catalyst support [23-28]. Ordered mesoporous structures (such as MCM-41 and SBA-15) with regular channel structures and high surface areas seem to be ideal for forming a scaffold in which metal nanoparticles can be supported on three-dimensional channels and hence their agglomeration can be prevented. For these reasons, preparation and use of metal nanoparticles deposited on such porous materials have received much attention in recent years [29].

An interesting catalyst for oxidation reaction is the combination of Au with a Pt-group metal. For example, a 2.5\% Au-2.5\% Pd/TiO bimetallic catalyst was used for oxidation of benzyl alcohol at $373 \mathrm{~K}$ with $\mathrm{O}_{2}$ as an oxidant in the absence of solvent. The $\mathrm{Au}-\mathrm{Pd} /$ $\mathrm{TiO}_{2}$ catalysts were very active for this reaction, and the selectivity to benzaldehyde was $\geq 96 \%$, with the only byproduct being benzyl benzoate. Enache et al. [30] concludes that the addition of Au into $\mathrm{Pd} / \mathrm{TiO}_{2}$ catalyst decreases the activity, but the $\mathrm{Au}-\mathrm{Pd} / \mathrm{TiO}_{2}$ catalyst retained high selectivity to benzaldehyde at a higher conversion rate. This feature was not observed with supported pure-Au and pure-Pd catalysts.

Alcohol oxidation with molecular oxygen on gold catalyst requires strongly basic medium under mild conditions [31,32]. To the best of our knowledge, no explanation regarding the actual role of hydroxyl anion in the reaction has been given in the current literatures. Carbonates (e.g., $\mathrm{K}_{2} \mathrm{CO}_{3}, \mathrm{Na}_{2} \mathrm{CO}_{3}$ ) are widely applied as 
weak bases in reactions involving proton extraction [32]. Therefore, the activity of solvent free liquid-phase oxidation of benzyl alcohol with $\mathrm{Na}_{2} \mathrm{CO}_{3}$ solution as promoter is investigated in this work.

Herein, we present Au/SBA-15 and Au-Pd/SBA-15 catalysts prepared by impregnation and grafting methods. It was observed that the metal nanoparticles of catalysts prepared by the grafting method can enter into pore channels of SBA-15 and the metal leaching was held back by geometric limit of the channel. The introduction of palladium into Au/SBA-15 made the gold particles become smaller and disperse more uniformly. The Au-Pd/SBA-15 catalyst prepared by the grafting method exhibited the best catalytic activity and stability in the oxidation of benzyl alcohol. We conclude that small and highly dispersed gold and palladium nanoparticles confined in the channels of mesoporous silica contribute to high reaction activity and the gold nanoparticles may not sinter under calcination or agglomerate in the reaction process.

\section{Experimental}

\subsection{Catalysts preparation}

\subsubsection{Direct grafting method}

SBA-15 was synthesized according to the published procedure [33,34]. $2.0 \mathrm{~g}$ of as-synthesized SBA-15 was suspended in $150 \mathrm{ml}$ of pure toluene under flowing $\mathrm{N}_{2}$, and then $10 \mathrm{ml}$ of MPTS (3-(mercaptopropyl)trimethoxylsilane) was added dropwise while stirring. The particles were recovered by evaporating the toluene after stirring continuously at $80^{\circ} \mathrm{C}$. Then the surfactant template occluded inside the sample was removed by $150 \mathrm{ml}$ ethanol extraction for $12 \mathrm{~h}$ and then calcination at $300{ }^{\circ} \mathrm{C}$ for $4 \mathrm{~h}$. Thus, the mesoporous silica functionalized with $\mathrm{Si}\left(\mathrm{CH}_{2}\right)_{3} \mathrm{SH}$ (assigned as M-SBA-15) were obtained. $2.0 \mathrm{~g}$ of M-SBA-15 was dried at $70{ }^{\circ} \mathrm{C}$ for $12 \mathrm{~h}$ before dispersion in $150 \mathrm{ml}$ of toluene. Then $6.0 \mathrm{ml}$ of APTS (aminopropyltriethoxylsilane) was added under stirring. The mixture obtained was stirred for another $12 \mathrm{~h}$ at room temperature and refluxed at $80^{\circ} \mathrm{C}$ for $8 \mathrm{~h}$. The recovered solid was washed with toluene and then with ethanol intensively to remove physically adsorbed APTS and toluene. Then the synthesized sample was denoted as A-M-SBA-15, after being vacuum-dried at $80^{\circ} \mathrm{C}$ for $6 \mathrm{~h}$. Reducing species were introduced by stirring $1.0 \mathrm{~g}$ A-M-SBA-15 in a $105 \mathrm{ml}$ mixture of formaldehyde, ethanol and water (formaldehyde/ethanol/water $=5: 20: 80, \mathrm{v} / \mathrm{v} / \mathrm{v}$ ) at $40{ }^{\circ} \mathrm{C}$ for $30 \mathrm{~min}$. The filtered solid was dried at $70{ }^{\circ} \mathrm{C}$ for $12 \mathrm{~h}$ and named as H-A-M-SBA15. To introduce Au, $1.0 \mathrm{~g}$ of $\mathrm{H}-\mathrm{A}-\mathrm{M}-\mathrm{SBA}-15$ was added into a mixture of ethanol and $2.3 \mathrm{ml}$ of $\mathrm{HAuCl}_{4}$ aqueous solution $(17.6 \mathrm{mg}$ $\mathrm{Au} / \mathrm{ml}$, ethanol/HAuCl 4 (aq) $=5: 1, \mathrm{v} / \mathrm{v}$ ). The $\mathrm{H}-\mathrm{A}-\mathrm{M}-\mathrm{SBA}-15 / \mathrm{HAuCl}_{4}$ mixture was then stirred at room temperature for $2 \mathrm{~h}$, dried at $70{ }^{\circ} \mathrm{C}$ for $24 \mathrm{~h}$ and calcined at $200{ }^{\circ} \mathrm{C}$ for $2 \mathrm{~h}$ to get sample DAuS- 1 . In the control experiments, the same procedure was followed except for the formaldehyde treatment. The synthesized sample was denoted as DAuS. When the $\mathrm{HAuCl}_{4}$ aqueous solution was replaced by $\mathrm{Pd}\left(\mathrm{NO}_{3}\right)_{2}$ aqueous solution $(0.39 \mathrm{mg} \mathrm{Pd} / \mathrm{ml}, 20 \mathrm{ml})$ similar to the procedure of DAuS preparation, the synthesized sample was denoted as DPdS. The resulting sample synthesized with $\mathrm{HAuCl}_{4}$ and $\mathrm{Pd}\left(\mathrm{NO}_{3}\right)_{2}$ aqueous solution together was denoted as DAuPdS.

\subsubsection{Impregnation method}

The as-synthesized SBA-15 was dried at $70{ }^{\circ} \mathrm{C}$ and calcined at $550{ }^{\circ} \mathrm{C}$ for $4 \mathrm{~h}$ to obtain SBA-15 powder. $1 \mathrm{M}$ sodium hydroxide solution was added into the chloroauric acid solution (17.6 mg Au/ $\mathrm{ml}, 2.5 \mathrm{ml}$ ) for adjusting the solution $\mathrm{pH}$ to 7 ; then $1.1 \mathrm{~g}$ of SBA-15 powder was added and aged at room temperature for $12 \mathrm{~h}$. The precipitates were washed several times, dried at $70{ }^{\circ} \mathrm{C}$ for $5 \mathrm{~h}$ and calcined at $200{ }^{\circ} \mathrm{C}$ for $2 \mathrm{~h}$. The obtained Au/SBA-15 sample was named as IMAuS. In the synthesis of $\mathrm{Au}-\mathrm{Pd} / \mathrm{SBA}-15$, the same procedure was followed but $\mathrm{Pd}\left(\mathrm{NO}_{3}\right)_{2}$ solution $(0.39 \mathrm{mg} \mathrm{Pd} / \mathrm{ml}$, $14 \mathrm{ml}$ ) was added to the precipitates containing chloroauric acid and SBA-15. The obtained Au-Pd/SBA-15 sample was named as IMAuPdS. The loadings of Au and Pd of all samples were $4.0 \mathrm{wt} \%$ and $0.5 \mathrm{wt} \%$, respectively.

\subsection{Catalyst characterizations}

Infrared spectra of the samples were record on Bruker Tensor27 using DRIFT technique, scanned from 4000 to $600 \mathrm{~cm}^{-1}$. Wide-angle XRD patterns were measured on a Rigaku powder diffractometer (D/MAX-RB) using $\mathrm{Cu} K \alpha$ radiation $(\lambda=0.15418 \mathrm{~nm}$ ) in the $2 \theta$ range of $10-70^{\circ}$ with a scanning rate of $4^{\circ} \mathrm{min}^{-1}$. Small-angle XRD was recorded on a SIEMENS D5005D powder diffraction system using $\mathrm{Cu}$ $\mathrm{K} \alpha$ radiation in the $2 \theta$ range of $0.7-6.0^{\circ}$ with a scanning step size of $0.02^{\circ}$. The textural properties of the samples were measured by $\mathrm{N}_{2}$ adsorption at liquid nitrogen temperature, using a gas adsorption analyzer NOVA 1200. Transmission electron microscopy (TEM) analysis was conducted using $\mathrm{H}-7500$ microscope operating with an acceleration voltage of $80 \mathrm{kV}$. The specimens were prepared by ultrasonication in ethanol, evaporating a drop of the resultant suspension onto a carbon support grid.

\subsection{Activity measurement of catalyst}

For atmospheric pressure oxidation of alcohols under air flow, the catalytic experiment was carried out at $80^{\circ} \mathrm{C}$, in a three-necked batch reactor fitted with a reflux condenser, water bath, thermocouple and magnetic stirrer. A mixture of $\mathrm{Na}_{2} \mathrm{CO}_{3}$ aqueous solution ( $\left.0.55 \mathrm{~mol} \mathrm{l}^{-1}, 25 \mathrm{ml}\right), 0.05 \mathrm{ml}$ decane (used as internal standard) and $0.2 \mathrm{~g}$ of catalyst was prepared in the three-necked flask. The $0.5 \mathrm{ml}$ of benzyl alcohol was then added into the solution and the resulting mixture was stirred at $80^{\circ} \mathrm{C}$ with a stirring speed of $800 \mathrm{rpm}$. After the reaction, the catalyst was removed from the reaction mixture by centrifugation; the products and the unconverted reactants were analyzed by gas chromatography with a flame ionization detector, using a HP-5 column.

\section{Results and discussion}

\subsection{Catalyst synthesis and characterization}

Fig. 1 exhibits selective intra-pore functionalization and graft of gold particles in pore channels of SBA-15. The synthesis of Au-Pd/SBA-15 by grafting method involves four sub-steps: (1) external grafting reaction of organosilane reagent 3-(mercaptopropyl)trimethoxylsilane (MPTS) with "as-synthesized SBA-15" containing P123 template; (2) calcination of SBA-15 to remove P123 and partial MPTS; (3) internal grafting reaction of aminopropyltriethoxylsilane (APTS) with mesoporous SBA-15 free of template; (4) grafting gold or palladium particles into the intrasurface of SBA-15 pore channels through inter molecular interaction between metals and amino groups. In the study of de Juan and Ruiz-Hitzky [35], they reported it was possible to specifically change the nature of the internal surface (pores) of MCM-41 following the similar sub-steps (steps 1-3). In the present study, firstly MPTS reacted with only external Si-OH before the removal of template $\mathrm{P} 123$. The $-\mathrm{SH}$ groups introduced by silylation covered the external surface by replacing $\mathrm{Si}-\mathrm{OH}$ groups. MPTS was selected because it was previously used to make functional monolayer [36]. Then P123 was removed by ethanol extraction and partial -SH groups can be removed by calcination at $300{ }^{\circ} \mathrm{C}$, which was testified by thermogravimetric analysis (TGA) of samples in the research of Margolese et al. [37]. The calcinations step removed 

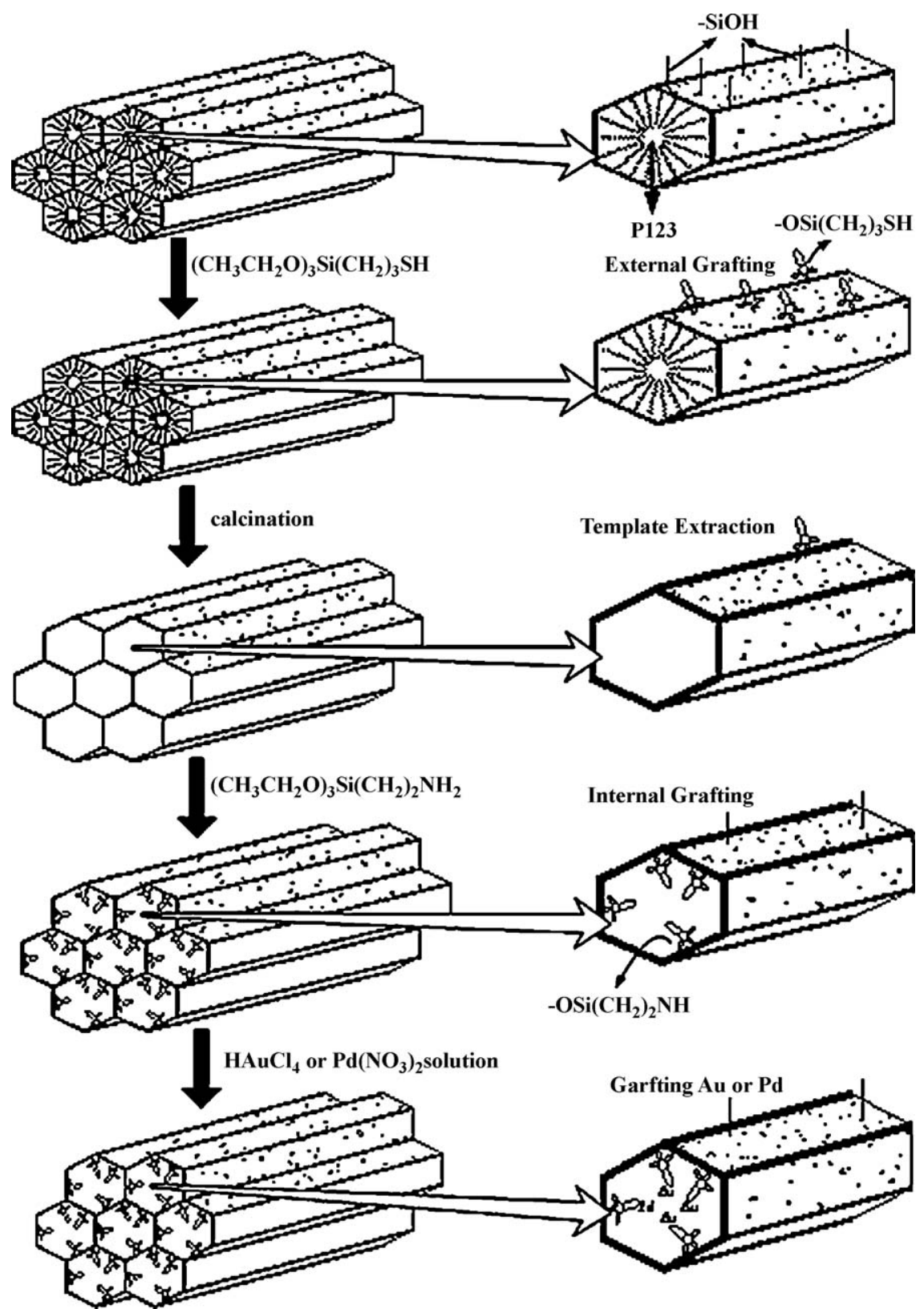

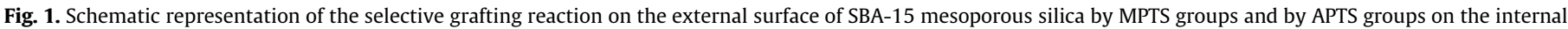
surface, and Au-Pd/SBA-15 sample was prepared by grafting gold and palladium.

-SH groups, and also removed the external $\mathrm{Si}-\mathrm{OH}$ attached by $-\mathrm{SH}$ groups. Next the SBA-15 derivative has little $\mathrm{Si}-\mathrm{OH}$ groups on external surface selectively grafted $-\mathrm{NH}$ groups on the intrasurface of the tubular pores of SBA-15 by reacting with APTS. Finally the gold or palladium particles entered into the pores of SBA-15 by the high affinity of - NH groups to binding metal.

According to the research of Sun et al. [38], $\mathrm{HCHO}$ was used to get metallic $\mathrm{Ag}$ from $\mathrm{Ag}\left(\mathrm{NH}_{3}\right)_{2} \mathrm{NO}_{3}$ precursor at relatively low temperature, which led to diverse distribution of silver nanoparticles in the channels of SBA-15. In the preparation of Au/SBA15 in this paper, using $\mathrm{HCHO}$ can get diverse dispersion of gold pseudospherical nanoparticles (refer to TEM image as Fig. 5).

Fig. 2 displays the FT-IR spectra of $\mathrm{Au}(\mathrm{Pd}) / \mathrm{SBA}-15$ samples. The concerted stretch of $\mathrm{Si}-\mathrm{O}-\mathrm{Si}$ gave rise to absorption at 1243, 1195, and a peak at $1083 \mathrm{~cm}^{-1}$ was as a result of partial ordering of the silicate framework on the pore surface. A peak at $3745 \mathrm{~cm}^{-1}$ was observed in all curves, indicating the presence of stretching vibrations of isolated silanol groups ( $\mathrm{Si}-\mathrm{OH})$ [39]. The IMAuS material showed a much less intense $3745 \mathrm{~cm}^{-1}$ peak, indicating a less population of isolated silanol groups. The intensity of peaks at $3745 \mathrm{~cm}^{-1}$ for isolated silanols of DAuS or DAuPdS weaken, indicating some silanol groups reacted with the organic siloxane and noble metal. For the $-\mathrm{NH}$ functionalized $\mathrm{Au}(\mathrm{Pd}) / \mathrm{SBA}-15$ prepared by grafting method (shown as spectrum c-f), in addition to the above peaks, a new infrared absorption band assigned to $\mathrm{NH}_{2}$ asymmetric bending was observed at $1602 \mathrm{~cm}^{-1}$ [40]. The vibration corresponding to the $-\mathrm{SH}$ group $\left(2580 \mathrm{~cm}^{-1}\right)$ was not observed, indicating the $-\mathrm{SH}$ group was removed in the calcination process [37]. The absorption band at $1630 \mathrm{~cm}^{-1}$ observed in all curves was attributed to the bending vibrations of adsorbed $\mathrm{H}_{2} \mathrm{O}$. The surface of DAuS and DAuPdS might be more hydrophilic due to the polar character of silanol groups, which was proved by more intensive deformational vibrations of adsorbed water molecules at ca. $1630 \mathrm{~cm}^{-1}$ in Fig. $2 \mathrm{~d}$ and f, respectively. The peaks between 2700 and $3000 \mathrm{~cm}^{-1}$ for spectra $\mathrm{c}, \mathrm{d}$, e and $\mathrm{f}$ can be assigned to the aliphatic $\mathrm{C}-\mathrm{H}$ stretching within the pores due to the introduction of 


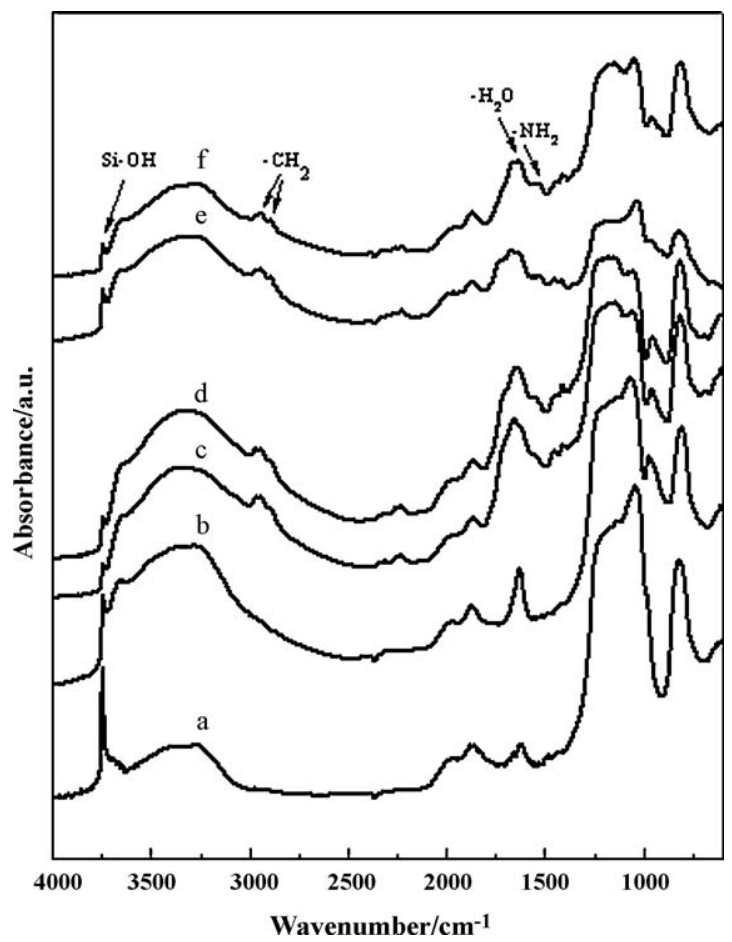

Fig. 2. FT-IR spectra of SBA-15 and Au/SBA-15 materials: (a) SBA-15, (b) IMAuS, (c) DAuS-1, (d) DAuS, (e) DPdS, and (f) DAuPdS.

methyl groups during silylation [41]. This is in accordance with the preparation model of $\mathrm{Au}(\mathrm{Pd}) / \mathrm{SBA}-15$ samples in Fig. 1.

Fig. 3A shows the small-angle XRD (X-ray powder diffraction) patterns of the $\mathrm{Au}(\mathrm{Pd}) / \mathrm{SBA}-15$ samples. All the SBA-15 and $\mathrm{Au}(\mathrm{Pd}) /$ SBA-15 samples exhibited very similar patterns where three wellresolved diffraction peaks due to 100,110 , and 200 reflections were observed. For the DAuS and DAuPdS samples, the XRD peaks increased in intensity due to the absence of scattering from the surfactant [42]. The peaks also shifted to higher $d$ spacing and to higher cell parameter " $a$ " (Table 1), indicating that the materials
Table 1

The structural parameters of SBA-15 and $\mathrm{Au}(\mathrm{Pd}) / \mathrm{SBA}-15$ materials.

\begin{tabular}{lcclll}
\hline Sample & $\begin{array}{l}d_{100} \\
(\mathrm{~nm})\end{array}$ & $a(\mathrm{~nm})$ & $\begin{array}{l}S(\mathrm{BET}) \\
\left(\mathrm{m}^{2} \mathrm{~g}^{-1}\right)\end{array}$ & $V\left(\mathrm{~cm}^{3} \mathrm{~g}^{-1}\right)$ & $\begin{array}{l}D(\mathrm{BJH}) \\
(\mathrm{nm})\end{array}$ \\
\hline SBA-15 & 9.815 & 11.33 & 939 & 1.26 & 6.4 \\
IMAuS & 9.221 & 10.65 & 496 & 0.95 & $3.4 / 6.6$ \\
IMAuPdS & 9.387 & 10.84 & 539 & 1.00 & $3.4 / 6.6$ \\
DAuS-1 & 10.42 & 12.03 & 272 & 0.36 & 3.4 \\
DAuS & 10.42 & 12.03 & 507 & 0.62 & 3.4 \\
DPdS & 10.42 & 12.03 & 448 & 0.47 & $3.4 / 6.2$ \\
DAuPdS & 10.21 & 11.79 & 274 & 0.33 & 3.4 \\
\hline
\end{tabular}

$d_{100}$ : the interplanar spacing of the $(100)$ plane; $a$ : the lattice parameter calculated by $a=2 d_{100} / \sqrt{3} ; S(B E T)$ : BET surface area calculated using experimental points at relative pressure of $P / P_{0}=0.05-0.25 ; V$ : pore volume, calculated by the $\mathrm{N}_{2}$ amount adsorbed at the highest $P / P_{0}(\sim 0.99) ; D(\mathrm{BJH})$ : pore size, calculated by $\mathrm{BJH}$ method.

underwent further condensation and constriction of the pores due to gold or palladium particles entering partially into the pores of SBA-15 [43].

The wide-angle XRD patterns of $\mathrm{Au}(\mathrm{Pd}) / \mathrm{SBA}-15$ materials prepared by grafting method are shown in Fig. 3B. The presence of characteristic diffraction lined at $2 \theta=38.2^{\circ}$, which can be assigned to the (1 111 ) planes of face centered cubic structure of gold, indicating that gold had crystallized [44]. In contrast to DAuS, the DAuPdS catalyst had relatively weaker diffraction lines for gold, indicating that gold agglomerates were low in the SBA-15 (Fig. $3 \mathrm{~B}(\mathrm{~g})$ ). It was observed that the synergistic effect of the addition of Pd to Au/SBA-15 catalyst decreased the size of gold nanoparticles. The peak at $33.7^{\circ}$ was assigned to crystalline PdO. The diffraction peak located between $\operatorname{Au}\left(\begin{array}{lll}1 & 1 & 1\end{array}\right)$ and $\operatorname{Pd}\left(\begin{array}{lll}1 & 1 & 1\end{array}\right)$ was assigned to the $\mathrm{Au}_{x} \mathrm{Pd}_{y}$ alloy phase [45]. $\mathrm{PdO}$ and $\mathrm{Pd}^{0}$ phases but no $\mathrm{Au}_{x} \mathrm{Pd}_{y}$ alloy phase were observed in DAuPdS sample. Yi et al. [46]. concluded that the Pd-Au mixtures formed a stable alloy with substantial enrichment in Au at $400-700{ }^{\circ} \mathrm{C}$. The DAuPdS sample was calcined at $200{ }^{\circ} \mathrm{C}$, so that the $\mathrm{Au}_{x} \mathrm{Pd}_{y}$ alloy phase did not exist.

Fig. 4A shows nitrogen adsorption/desorption isotherms of SBA-15 and various $\mathrm{Au}(\mathrm{Pd}) / \mathrm{SBA}-15$ samples. All the isotherms are of type IV [47], which is a characteristic of mesoporous materials. SBA-15 shows a hysteresis loop which typically features a

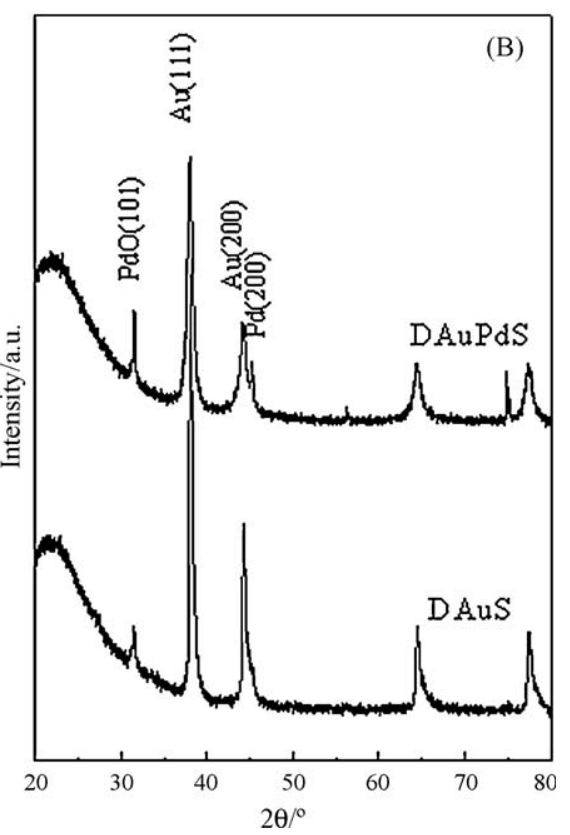

Fig. 3. (A) Small-angle and (B) wide-angle XRD patterns of Au/SBA-15 materials: (a) SBA-15, (b) IMAuS, (c) IMAuPdS, (d) DAuS-1, (e) DAuS, (f) DPdS, and (g) DAuPdS. 

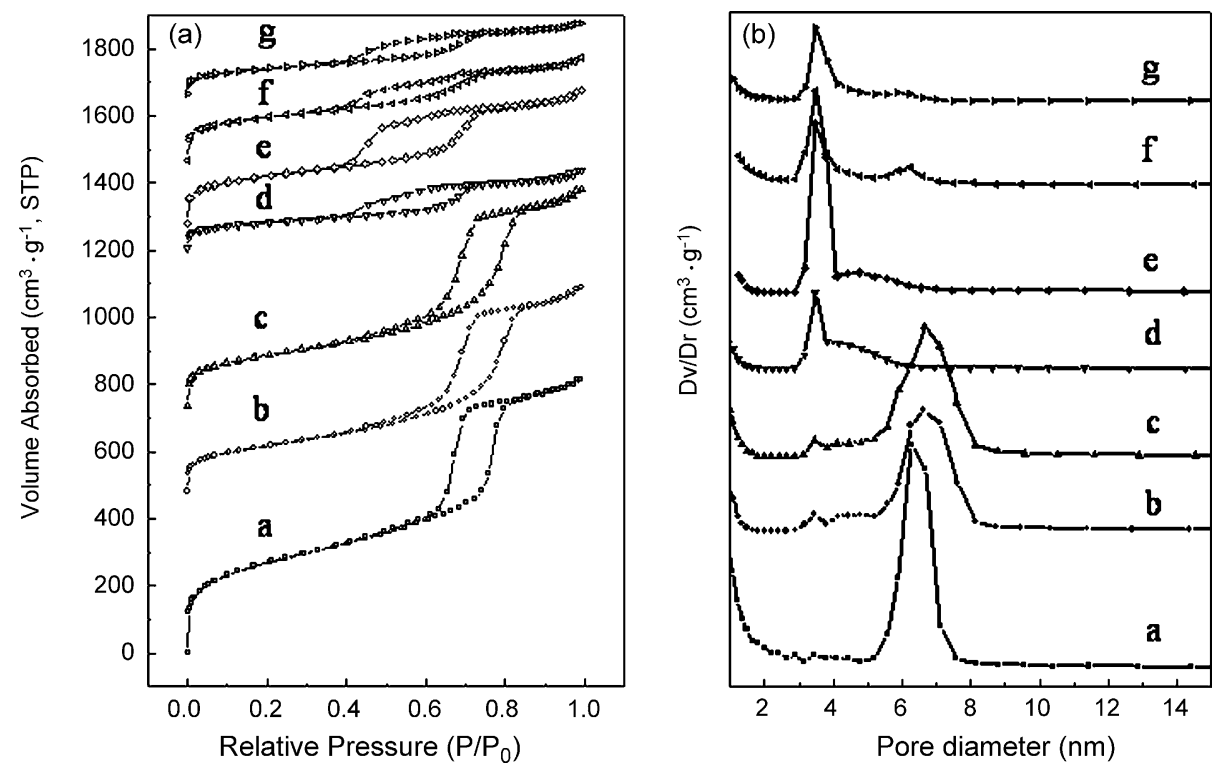

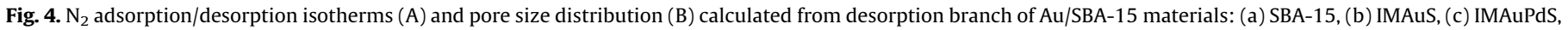

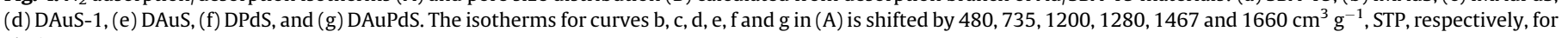
clarity.

two-dimensional $P 6 \mathrm{~mm}$ structure formed by open cylindrical mesopores (Fig. 4A(a)). The isotherms of IMAuS and IMAuPdS are identical to the isotherm of SBA-15 (Fig. $4 \mathrm{~A}(\mathrm{~b})$ and (c)). The nitrogen adsorption isotherms of SBA-15 and IMAuS exhibit H1type hysteresis loop and features a sharp step in the $P / P_{0}$ range of $0.55-0.8$, the sharpness of this step is indicative of the uniformity of the pore size. However, the hysteresis loops of DAuS-1, DAuS, DPdS and DAuPdS become smaller, and position of the step shifts towards lower relative pressure in the range of $0.3-0.7$ (as observed in Fig. $4 \mathrm{~A}(\mathrm{~d})-(\mathrm{g}))$, indicating that a smaller pore size is formed. This could be explained by two reasons: firstly, the methyl groups of APTS were introduced during silylation. Secondly, the gold or palladium nanoparticles entered into the pore partially. Physical properties/structural parameters of samples derived from the nitrogen isotherms are listed in Table 1 and the pore size distribution calculated from desorption branch is shown in Fig. 4B. The specific surface area and pore volume decrease as a result of loading noble metal particles. The reduction in pore size for functionalized $\mathrm{Au}(\mathrm{Pd}) / \mathrm{SBA}-15$ samples suggests that most of the functional groups and noble metal nanoparticles have been distributed inside the pores of SBA-15.

Fig. 5 shows the TEM images of the Au(Pd)/SBA-15 materials. The sample IMAuS revealed well-developed parallel pore channels with gold particles (in the range of $10-50 \mathrm{~nm}$ ) well dispersed on the intra-surface of SBA-15. The gold particles of IMAuS did not exhibit pseudospherical particles but grew along the directions of channels (Fig. 5a). The gold or palladium pseudospherical nanoparticles of IMAuPdS dispersed better compared to IMAuS but did not enter into the channels of SBA-15 (Fig. 5b). The added formaldehyde may block the channels of SBA-15 and contribute to the large and badly dispersed gold particles (around $50 \mathrm{~nm}$ ) of DAuS-1 (Fig. 5c). The gold particles of DAuS sample were less than $10 \mathrm{~nm}$ and dispersed uniformly (Fig. 5d). When palladium was added to prepare DAuPdS sample, gold and palladium nanoparticles $(5 \mathrm{~nm}$ ) entered into the channels of SBA-15 (Fig. 5e and f). Results showed that palladium added in Au/SBA-15 can reduce the size of gold nanoparticles and make the particles disperse comparatively uniform. We propose that, in the Au-Pd/SBA-15 sample prepared by grafting method, the gold and palladium nanoparticles can enter into the pores and their particle sizes were limited by the space between the channels.

\subsection{Catalyst performances for the oxidation of benzyl alcohols}

$\mathrm{Au}(\mathrm{Pd}) / \mathrm{SBA}-15$ catalysts were initially investigated for oxidation of benzyl alcohol at $353 \mathrm{~K}$ with air as oxidant in the existence of base media. Catalysis performances of materials are listed in Table 2 . The effect of adding Pd to Au/SBA-15 catalyst was apparent in this study. The IMAuS catalyst led to a turnover frequency (TOF) of 198 and the selectivity to benzaldehyde was 99\%. The IMAuPdS was more active than IMAuS for benzyl alcohol oxidation and the TOF reached to 625 in $2 \mathrm{~h}$ with the selectivity slightly decreasing to $96 \%$. For the DAuPdS catalysts, a conversion rate of $20.5 \%$ was observed which corresponded to a TOF of 990 after first $2 \mathrm{~h}$ of reaction, while the selectivity to benzaldehyde was $98 \%$. TOF decreased to 308 when the DAuS was used. This concluded that the addition of Pd to Au/SBA-15 catalysts increased the activity and retained high selectivity to benzaldehyde. On basis of the wide-angle XRD results above, we concluded that the active phase of DAuS was metallic $\mathrm{Au}$, and the active phases of DAuPdS were metallic Au, Pd and $\mathrm{PdO}$ phase, respectively without the $\mathrm{Au}_{x} \mathrm{Pd}_{y}$ alloy phase. The size of gold particles in Au-Pd/SBA-15 catalysts were smaller than that in Au/SBA-15 catalysts due to the synergetic effect of metallic Au and Pd. Considering that the DPdS gave lower activity, one of the key factors for the high activity of DAuPdS must be its nanosize of gold nanoparticles that were dispersed more uniformly in Au-Pd bimetallic catalysts. The DAuS- 1 catalyst gave the worst activity and the TOF only reached to 49 , which was attributed to the bigger gold particles presented in DAuS-1 catalyst.

The Au-Pd/SBA-15 catalyst prepared by the grafting method (DAuPdS) was very active for this reaction, and the activity of the catalyst did not decrease with time. In contrast, the activity of Au-Pd/SBA-15 catalyst prepared by impregnation (IMAuPdS) decreased with time. One of the problems of heterogeneous catalyst operated in liquid-phase systems is the active components leaching which can result in the deactivation of the catalyst [30]. Therefore high activity and stability of the DAuPdS catalyst is probably due to solid connection between Au or Pd and SBA-15 materials which can prevent $\mathrm{Au}$ or Pd from their leaching into solution.

Achieving precise control of the gold and palladium particle size and overall particle size distribution of catalysts is one of the most important challenges to provide excellent catalysis properties [30]. 

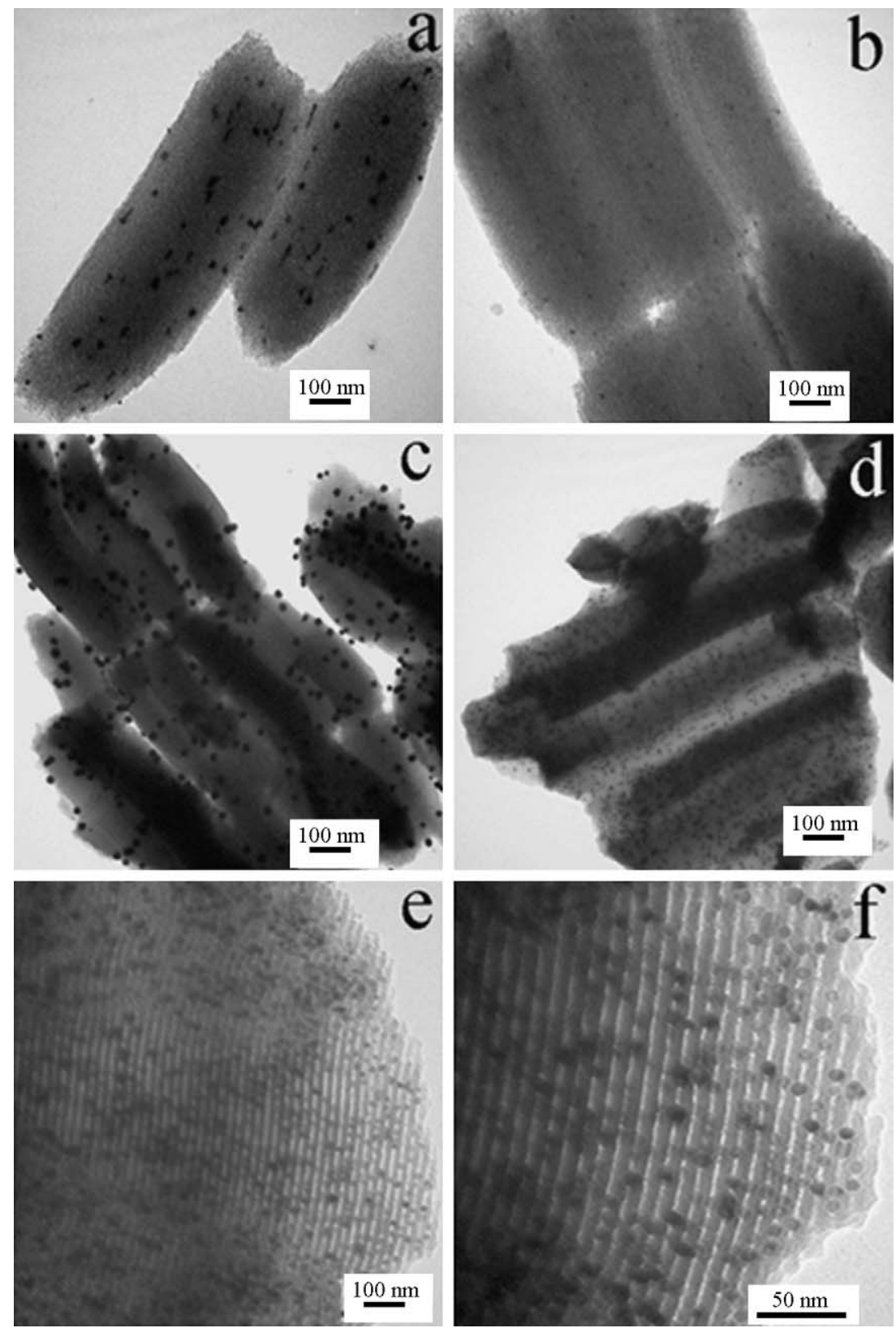

Fig. 5. TEM images of Au/SBA-15 materials: (a) IMAuS, (b) IMAuPdS, (c) DAuS-1, (d) DAuS, and (e and f) DAuPdS.

Hu et al. [48] reported that gold nanoparticles confined in the walls of mesoporous silica catalysts were stable under the reaction condition for aerobic oxidation of alcohol. Karimi et al. [8] demonstrated that the Pd/SBA-15 catalyst with organic ligands can be prepared by using $\mathrm{Pd}(\mathrm{OAc})_{2}$ as a precursor and the palladium particles can be distributed inside the channels of SBA15 to produce a durable catalyst. In our work, the grafting method provided DAuPdS sample a technique of uniformly distributing the

Table 2

Comparative reaction data for selective oxidation of benzyl alcohol.

\begin{tabular}{|c|c|c|c|c|c|c|c|c|c|}
\hline \multirow[t]{2}{*}{ Catalysts } & \multicolumn{4}{|c|}{ Conversion (\%) } & \multicolumn{4}{|c|}{ Selectivity (\%) } & \multirow[t]{2}{*}{$\mathrm{TOF}\left(\mathrm{h}^{-1}\right)$} \\
\hline & $2 \mathrm{~h}$ & $4 \mathrm{~h}$ & $6 \mathrm{~h}$ & $8 \mathrm{~h}$ & $2 \mathrm{~h}$ & $4 \mathrm{~h}$ & $6 \mathrm{~h}$ & $8 \mathrm{~h}$ & \\
\hline IMAuS & 4.05 & 0.55 & 0.67 & 1.29 & 99 & 98 & 98 & 98 & 198 \\
\hline IMAuPdS & 12.8 & 10.2 & 10.2 & 10.5 & 96 & 96 & 95 & 95 & 625 \\
\hline DAuS-1 & 1.01 & 1.62 & 1.57 & 1.41 & 99 & 98 & 98 & 98 & 49 \\
\hline DAuS & 6.30 & 6.99 & 6.50 & 6.42 & 98 & 97 & 97 & 97 & 308 \\
\hline DPdS & 0.25 & 0.26 & 0.26 & 0.29 & 99 & 99 & 99 & 99 & 12 \\
\hline DAuPdS & 20.5 & 30.4 & 35.5 & 39.2 & 98 & 97 & 97 & 97 & 990 \\
\hline
\end{tabular}

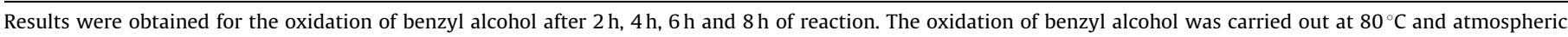
pressure under air flow. TOF was measured after first $2.0 \mathrm{~h}$ of reaction. 
gold and palladium species throughout the SBA-15 to ensure the controlled formation of nanoparticles mostly inside the ordered mesoporous channels of SBA-15 (Fig. 5e and f). It may be also concluded that the gold nanoparticles in the size-restricted mesopores of the SBA-15 can prevent both leaching and agglomeration of gold nanoparticles, which resulted in high catalytic stability of DAuPdS.

\section{Conclusions}

In summary, Au-Pd/SBA-15 catalyst was successfully synthesized by using the grafting method and was found to be highly active towards selective oxidation of benzyl alcohol to benzaldehyde. Our results show that the introduction of palladium to $\mathrm{Au} / \mathrm{SBA}-15$ could decrease the size of gold particles due to the synergetic effect of these two metals, and small gold nanoparticles render a high activity of benzyl alcohol oxidation. Furthermore, the added palladium into $\mathrm{Au} / \mathrm{SBA}-15$ does not reduce the selectivity of benzyl alcohol to benzaldehyde. The gold nanoparticles produced inside the sizerestricted mesopores of SBA-15 can prevent their agglomeration and leaching and lead to enhanced stability of catalyst.

\section{Acknowledgements}

The National Science Fund for Distinguished Young Scholars (No. 20725723), the National Basic Research Program of China (No. 2010CB732300), and National High Technology Research and Development Program of China (No. 2006AA06A310) are gratefully acknowledged.

\section{References}

[1] M. Hudlicky, Oxidation in Organic Chemistry, American Chemical Society, Washington, DC, 1990

[2] R.V. Stevens, K.T. Chapman, H.N. Weller, J. Org. Chem. 45 (1980) 2030-2032.

[3] J.R. Holum, J. Org. Chem. 26 (1961) 4814-4816.

[4] D.G. Lee, U.A. Spitzer, J. Org. Chem. 35 (1970) 3589-3590.

[5] R.J. Highet, W.C. Wildman, J. Am. Chem. Soc. 77 (1955) 4399-4401.

[6] F.M. Menger, C. Lee, Tetrahedron Lett. 22 (1981) 1655-1656.

[7] K. Mori, T. Hara, K. Mizugaki, K. Ebitani, K. Kaneda, J. Am. Chem. Soc. 126 (2004) 10657-10666.

[8] B. Karimi, S. Abedi, J.H. Clark, V. Budarin, Angew. Chem. Int. Ed. 45 (2006) 47764779 .

[9] N. Jamwal, M. Gupta, S. Paul, Green Chem. 10 (2008) 999-1003.

[10] K. Yamaguchi, N. Mizuno, Angew. Chem. Int. Ed. 41 (2002) 4538-4542.

[11] K. Yamaguchi, N. Mizuno, Chem. Eur. J. 9 (2003) 4353-4361.

[12] A. Dijksman, A. Marino-González, A.M. I Payeras, I.W.C.E. Arends, R.A. Sheldon, J. Am. Chem. Soc. 123 (2001) 6826-6833.

[13] I.E. Marko, P.R. Giles, M. Tsukazaki, S.M. Brown, C.J. Urch, Science 274 (1996) 2044-2046.
[14] I.E. Marko, P.R. Giles, M. Tsukazaki, I. Chelle-Regnaut, A. Gautier, S.M. Brown, C.J. Urch, J. Org. Chem. 64 (1999) 2433-2439.

[15] M. Haruta, T. Kobayashi, H. Sano, N. Yamada, Chem. Lett. 16 (1987) 405-408.

[16] A. Abad, P. Concepción, A. Corma, H. García, Angew. Chem. Int. Ed. 44 (2005) 4066-4069.

[17] H. Miyamura, R. Matsubara, Y. Miyazaki, S. Kobayashi, Angew. Chem. Int. Ed. 46 (2007) 4151-4154

[18] F.Z. Su, Y.M. Liu, L.C. Wang, Y. Cao, H.Y. He, K.N. Fan, Angew. Chem. Int. Ed. 47 (2008) 334-337.

[19] J.M. Campelo, T.D. Conesa, M.J. Gracia, M.J. Jurado, R. Luque, J.M. Marinas, A.A. Romero, Green Chem. 10 (2008) 853-858.

[20] J.J. Zhu, J.L. Figueiredo, J.L. Faria, Catal. Commun. 9 (2008) 2395-2397.

[21] M. Bron, R. Holze, Surf. Sci. 457 (2000) 178-184.

[22] F. Boccuzzi, A. Chiorino, M. Manzoli, D. Andreeva, T. Tabakova, J. Catal. 188 (1999) 176-185.

[23] L.-C. Wang, Q. Liu, X.-S. Huang, Y.-M. Liu, Y. Cao, K.-N. Fan, Appl. Catal. B: Environ. 88 (2009) 204-212.

[24] M. Huruta, M. Date, Appl. Catal. A: Gen. 222 (2001) 427-437.

[25] I. Dobrosz-Gómez, I. Kocemba, J.M. Rynkowski, Appl. Catal. B: Environ. 88 (2009) 83-97.

[26] E. Seker, E. Gulari, Appl. Catal. A: Gen. 232 (2002) 203-217.

[27] F. Zane, V. Trevisan, F. Pinna, M. Signoretto, F. Menegazzo, Appl. Catal. B: Environ. 89 (2009) 303-308.

[28] X.-S. Huang, H. Sun, L.-C. Wang, Y.-M.K. Liu, N. Fan, Y. Cao, Appl. Catal. B: Environ. 90 (2009) 224-232.

[29] S. Mandal, D. Roy, R.V. Chaudhari, M. Sastry, Chem. Mater. 16 (2004) 37143724.

[30] D.I. Enache, J.K. Edwaeds, P. Landon, B. Solaona-Espriu, A.F. Carley, A.A. Herzing, M. Watanabe, C.J. Kiely, D.W. Knight, G.J. Hutching, Science 311 (2006) 362-365.

[31] S. Carrettin, P. McMorn, P. Johnston, K. Griffin, C.J. Kiely, G.J. Hutchings, J. Phys. Chem. Chem. Phys. 5 (2003) 1329-1336.

[32] N. Zheng, G.D. Stucky, Chem. Commun. (2007) 3862-3864.

[33] D. Zhao, Q. Huo, J. Feng, B.F. Chemlka, G.D. Stucky, J. Am. Chem. Soc. 120 (1998) 6024-6036.

[34] D. Zhao, J. Feng, Q. Huo, N. Melosh, G.H. Fredrickson, B.F. Chemlkav, G.D. Stucky, Science 279 (1998) 548-552.

[35] F. de Juan, E. Ruiz-Hitzky, Adv. Mater. 12 (2000) 430-432.

[36] J. Liu, X.D. Feng, G.E. Fryxell, L.-Q. Wang, A.Y. Kim, M.L. Gong, Adv. Mater. 10 (1998) 161-165.

[37] D. Margolese, J.A. Melero, S.C. Christiansen, B.F. Chmelka, G.D. Stucky, Chem. Mater. 12 (2000) 2448-2459.

[38] J.M. Sun, D. Ma, H. Zhang, X.M. Liu, X.W. Han, X.H. Bao, G. Weinberg, N. Pfänder, D.S. Su, J. Am. Chem. Soc. 128 (2006) 15756-15764.

[39] J.J. Li, X.Y. Xu, Z.P. Hao, W. Zhao, J. Porous Mater. 15 (2008) 163-169.

[40] S.W. Song, K. Hidajat, S. Kawi, Langmuir 21 (2005) 9568-9575.

[41] S. Fiorolli, B. Onida, C. Barolo, G. Viscardi, D. Brunel, E. Garrone, Langmuir 23 (2007) 2261-2268.

[42] H.F. Yang, Q.Y. Lu, F. Gao, Q.H. Shi, Y. Yan, F.Q. Zhang, S.H. Xie, B. Tu, D.Y. Zhao, Adv. Funct. Mater. 15 (2005) 1377-1384.

[43] L.H. Hu, S.F. Ji, Z. Jiang, H.L. Song, P.Y. Wu, Q.Q. Liu, J. Phys. Chem. C 111 (2007) 15173-15184.

[44] Z.H. Suo, C.Y. Ma, M.S. Jin, T. He, L.D. An, Catal. Commun. 9 (2008) 21872190.

[45] A.M. Venezia, V.L. Parola, G. Deganello, B. Pawelec, J.L.G. Fierro, J. Catal. 215 (2003) 317-325.

[46] C.-W. Yi, K. Luo, T. Wei, D.W. Goodman, J. Phys. Chem. B 109 (2005) 18535-18540.

[47] K.S.W. Sing, D.H. Evrett, R.A.W. Haul, L. Moscou, R.A. Pierotti, J. Rouqérol, T. Siemieniewska, Pure Appl. Chem. 57 (1985) 603-619.

[48] J.C. Hu, L.F. Chen, K.K. Zhu, A. Suchopar, R. Richards, Catal. Today 122 (2007) 277283. 